\title{
Small is Insightful: A Method for the Microanalysis of Behaviour and Communication
}

\section{Colin R Griffiths}

The School of Nursing and Midwifery, Trinity College, Dublin, Ireland

*Corresponding author: Colin R Griffiths, The School of Nursing and Midwifery, Trinity College Dublin, 24 D'Olier street, Dublin 2, Ireland, Tel: 0035318963115; E-mail: colin.griffiths@tcd.ie

Received date: Aug 27, 2015; Accepted date: Sep 22, 2015; Published date: Sep 30, 2015

Copyright: ( 2015 Griffiths CR. This is an open-access article distributed under the terms of the Creative Commons Attribution License, which permits unrestricted use, distribution, and reproduction in any medium, provided the original author and source are credited.

\begin{abstract}
The purpose of this article is to describe a method of examining observational data that is obtained through video recording, which allows for the identification of precise micro behaviors. The article describes the use of video as a data gathering tool, the associated transcription of the data into narrative format and the analytic method. Both verbal and non-verbal micro data were obtained and the capturing and analysis of both are discussed in detail. The data was composed of micro-behaviors and micro-communications of two communication dyads both of which consisted of one person with profound intellectual and multiple disability and one non-disabled teacher or nurse. Classic Glaserian grounded theory was used to analyse the narrative data. The method enabled the identification of behaviors of the participants, their communications, the sequences in which they occurred and the interrelationships at a micro level. Taken as a whole the method can reveal previously hidden information about what individuals do and how they behave in dyads and in groups and this has applications in nursing, special needs education and other fields in which human interaction is paramount.
\end{abstract}

Keywords: Communication; Grounded theory; Microanalysis; Video

\section{Abbreviations \\ PIMD: Profound Intellectual and Multiple Disability}

\section{Introduction}

To achieve the aim of the current study, the nature of micro data that can be obtained by observational methods has been examined. In the context of a qualitative methodology the article explains how data can be developed from video derived micro analyzed observations. The article briefly explains the research study for which the method was developed. The main body describes in detail the data gathering and transcription methods and explains how a narrative framework was developed to hold the data. This is illustrated by using some exemplars. The data analysis process is then examined in detail and reference is made to the development of theory that is grounded in the data [1]. Finally the implications of such a method for the description of nursing practice and also for theory building are considered. In conclusion, the methodology that was implemented in the current study for analysis of micro-behavior may be considered as an illuminating exploratory tool for future healthcare, behavioral, and social science research.

\section{Theoretical context}

It has been said that the development of a method that can describe precise, micro analytic observational data is the most pressing matter in qualitative inquiry [2]. In this opening section of the article some of the literature on this topic is examined this includes the question of what constitutes qualitative micro data, how it can be sourced through the use of video and how description and theory can be derived from such data.

\section{Micro data}

Micro data is defined as observational data that is collected on one individual or statistical unit [3]. That definition can be elaborated as "data on the characteristics of units of a population, such as individuals, households, or establishments, collected by a census, survey, or experiment" [4]. These definitions allude to the smallness of the data where one individual constitutes the smallest data item. The definitions do not take account of the relative size of a unit of behavior. The question of reducing micro data to as small an aspect of an individual's behavior as is possible is central to the inquiry in this article. Therefore for the purposes of this article one item of behavioral micro data is defined as being constituted as "a discrete behavioral event that can be isolated and identified through observation and which cannot be further broken down". The characteristics of micro data in the behavioral arena are that it is often unnoticed, takes place very rapidly and consists of small behaviors, a subsection of which are micro-communications. Examples of the latter are difficult to find in the literature however micro-behaviors are more commonly referred to and research on the social interaction of children offers many examples of micro-behaviors. Micro-behaviors comprise eye gaze, voice tone, facial expression [5], bodily movements, gestures and vocal rhythm [6], smiles, head movements and eye contact [7].

\section{Invisibility}

Micro data is by its nature generally unnoticed in ordinary interaction. It goes on under the radar and is apparently not registered at a conscious level; it is mundane, part of the normal behaviors of an individual and therefore might not be noticed simply because of its normality [8]. Non-verbal behaviors which constitute the manifestation of the vast majority of brain activity according to Pally take place outside of surfaced conscious awareness and therefore influence the behavior of an individual in a way that the person does 
not register consciously [9]. A second characteristic of the type of behaviors that constitute micro data is that they tend to occur very rapidly [8]. Shimmerlik agrees suggesting that interaction between individuals is constantly in flux and that communications tend to be brief and responded to very rapidly [6]. This latter point is important in that the speed with which an event or a behavior can happen and then stop has the effect of making the behavior or communication invisible. By way of example eye gaze has been noted as being a microbehavior. Eye gaze can be gauged by measuring the saccades of an individual. Saccades are rapid ballistic changes that in eye position. They can occur up to three or four time per second [10], such rapid movements of the eye are however very difficult to observe in real time interaction.

\section{Video as a data gathering tool}

Video is a way of making detailed observations of behaviors. Video recording offers the capacity to gather multimodal representations of the action that is observed [11], that is, it allows for the observation of the full range of verbal and non-verbal behaviors and the often intricate interactions between these differing modes of expression, which are expressed as the complex dynamics of the communication process [11]. Video permits the observation of every action and utterance that research participants make [12], it also permits data to be obtained on an individual's behavior [13] and affective states [14] and enables the fine grained detail of what is observed to be noted [15]. The use of video recording of interactions, as opposed to simply audio taping them, locates language as one semiotic tool among a range of semiotic modes [11] and reveals the importance of non-verbal methods of expression and communication.

\section{Materials and Method}

The method was developed to understand the way in which people with profound intellectual and multiple disabilities communicate. Specifically the study was carried out so that a detailed examination could be made of the dyadic interactions of people with PIMD and the people who care for and teach them. People with profound intellectual and multiple disabilities require multiple supports to partake in and engage with the activities of daily life so that they can attain a high quality of life. They have such pervasive disability that those standardized tests that currently exist do not assess their capacities in a meaningful manner [16], furthermore their interactions are largely non-verbal and their communications are often difficult to discern and even more difficult to interpret. Because of this severe level of disability there is frequently an apparent communication gulf between the understandings of those people who interact with them and the persons with PIMD themselves. This communication gulf consists largely of a mutual inability to interpret the interactions of the other.

The fieldwork for the study was carried out in a developmental disability center in Ireland, that is, a school for children and adolescents under the age of 25 years who have severe and profound intellectual disability. Developmental disability centers which were staffed by a multidisciplinary mix of nurses, teachers and allied health professionals offered a broad, activity based curriculum that was tailored to the educational and life skill needs of the students. The centre in question was open from Monday to Friday from 8.30 AM until $5 \mathrm{PM}$ and the observations were conducted over a period of several weeks. Videotapes were made of three dyads each of which consisted of a teacher or health care worker and a person with PIMD. Each tape lasted for one hour and the participants were filmed where they were engaged in a variety of different activities such as having a cup of tea, painting, carrying out physical games, mat based movements, singing songs and telling stories. Of the three hours of videotape 25 minutes was selected for transcription from the tapes of two of the three dyads.

\section{Data collection}

After obtaining ethical permissions from the university faculty which was supervising the study and from the service that ran the developmental disability center as well as informed consent from the non-disabled participants and proxy informed consent from the parents or in one case grandparent of the disabled participants the author made first contact with the people in the center. Several meetings took place between author and the staff and students who had PIMD with a view to telling them about the research project and how it was to be carried out. The aim of the initial meetings was to obtain permission from the individual participants to take part in the study and also to enable them to get to know me. The meetings were successful and permissions were obtained from the staff and by proxy from the parents of the persons with PIMD. Data collection took place during school hours in the developmental disability center. On days when the author was filming I arrived early in the morning and set up the camera on its tripod so that its location provided a good view of the proceedings in the room but also was located at the edge of the room and did not dominate the room. A JVC-GR-D240 digital video camera which recorded the film to a standard JVC 60 minute videotape was used. Subsequently data was transferred to a Packard Bell Easynote laptop computer. Making the film required a high degree of vigilance as the author had to be constantly behind the viewfinder of the camera so that I could be sure that the camera was positioned correctly and filming the action and also with a view to ensuring that the zoom function recorded the relevant degree of detail. Although two of the three participants with PIMD were in wheelchairs the action moved around to some degree, which meant that not only were changes of camera direction quite frequent but also on one or two occasions the camera had to be moved around the room. In making the film I was aware that a balance had to be maintained between filming the totality of the action of the two people in the interaction and at the same time capturing the fine micro-behaviors that constituted the detail of the interaction, this required constant vigilance on my part.

\section{Data transcription}

Data was imported into Ulead studio 7 a video editing software package that enables film that is captured on videotape to be downloaded to a hard drive and edited in various ways. The software package enabled the film to be played at any speed required. Thus the film could be played at normal speed, played slowly or run on a frame by frame basis. Each frame constitutes the action of 1/24th second, analysis of which meant that it was possible to capture the very fine detail of each behavior, the sequences of behaviors and the relationship between behaviors. Examination of the film at such detail also meant the attention of participants could be tracked very closely through observation of the eye gaze and the saccades of each participant. A list of typical target communicative behaviors was compiled from the literature, these comprised vocalisations such as crying, babbling, moaning, laughing, facial and eye expressions such as gazing toward a person, joint attention, winking, smiling, and a blank stare and also body movements and gestures such as turning one's head, sitting upright, moving limbs, pointing, and turning [17-19]. Some other 
Page 3 of 7

typical behaviors were identified that were not pre-determined as likely to be observed these were: inflexions of posture, pauses, and tentative utterances.

\section{Development of the narrative framework}

The data that emerged as the video record was transcribed was related to the concept of 'thick description' [20,21]. Thick transcription is an ethnographic tool that can be used to develop theory and interpret culture [22]; it can be of use in sorting out how the inherent structures in the interaction process are rooted in the social interaction of the situation. Thick description starts with a transcription of what is said and done in an interaction in meticulous detail [22]. The aim is to "capture events and illuminate possible features of the data which are not yet known to be features" [23]. An assumption that underpinned the search for such detail was that many micro communications went unnoticed by participants in the interactions. Thus the data represented visual and auditory events on a macro level and also on a very detailed micro level. To ensure that the transcription captured not only the micro events and behaviors but also that they were transcribed in the exact sequence in which they happened a framework was put together into which the transcribed narrative could be inserted. This framework identified the date and time of the recording, the initials of the pseudonym of the participants, the second in which each event was located and the recording number which located the incident in the tape. The framework presented all transcribed data as rigorously as possible; it sought to identify the verbal and non-verbal behaviors of each participant in the exact sequence in which they occurred. The framework was designed to overcome the problem identified by Flewitt who noted that "visual and audio data representations often need to portray co-occurrence, yet juxtaposing multisensory, dynamic spatial events in two dimensional written research reports can result in cumbersome formats that text readers struggle to interpret" [11]. Spoken words and sentences that participants uttered were written verbatim into the framework, sounds that were vocalisations but not words were written down as orthographic approximations. Non-verbal behaviors were described as they happened and in sequence with verbal behaviors.

Table 1 presents an example of a data transcript. JM-John Moore (not his real name) has a severe intellectual disability. He is on a gym mat on the floor of the classroom. A feedback game is in progress. KMKate Mooney (the staff, also not her real name) is attempting to induce John to press a large plastic switch. When pressed the switch speaks John's name. The recording numbers in the left column denote minute and second. Indicators in brackets are for [l] left or [r] right, spoken words and vocalizations are denoted in italics.

\begin{tabular}{|c|c|c|c|c|c|c|}
\hline \multicolumn{7}{|c|}{ Event---JM is playing games with a large switch, he is lying face forward on a mat in a classroom. KM is sat down nearby. } \\
\hline & Participant JM & & & Participant KM & & \\
\hline Recording Number & Non verbal & & Verbal & Non Verbal & Verbal & Comments \\
\hline \multirow{6}{*}{17.24} & Eye Gaze & Looking at KM & & \multirow{6}{*}{$\begin{array}{l}\text { Sat on mat on her haunches } \\
\text { supported by her [l] hand which } \\
\text { is on the floor, holding the switch } \\
\text { in her [r] which is on the mat. } \\
\text { [She had just asked JM to press } \\
\text { the switch]. }\end{array}$} & & \multirow{6}{*}{$\begin{array}{l}\text { Background noises of } \\
\text { children playing in the } \\
\text { yard outside and } \\
\text { people talking in the } \\
\text { room }\end{array}$} \\
\hline & Facial Expression & & & & & \\
\hline & Head Movement & & & & & \\
\hline & Arm movement & $\begin{array}{l}\text { Hands clasped in } \\
\text { front of him }\end{array}$ & & & & \\
\hline & Leg movement & & & & & \\
\hline & Other & $\begin{array}{l}\mathrm{JM} \text { is lying face } \\
\text { forward on mat } \\
\text { resting on his } \\
\text { elbows looking up } \\
\text { at KM }\end{array}$ & & & & \\
\hline \multirow{6}{*}{17.25} & Eye Gaze & & & \multirow{6}{*}{ 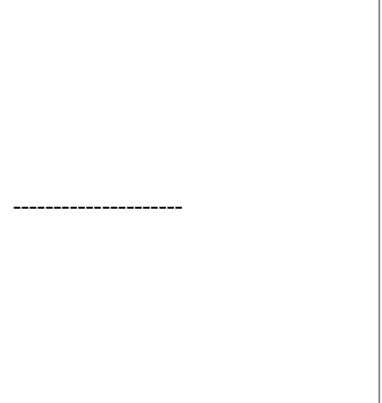 } & & \\
\hline & Facial Expression & & & & & \\
\hline & Head Movement & $\begin{array}{l}\text { Goes down a bit } \\
\text { looks [I] }\end{array}$ & & & & \\
\hline & Arm movement & ------- & & & & \\
\hline & Leg movement & $\begin{array}{l}\text { Slight [l] foot } \\
\text { movement. }\end{array}$ & & & & \\
\hline & Other & & & & & \\
\hline \multirow{2}{*}{17.26} & Eye Gaze & & & \multirow{2}{*}{$\begin{array}{l}\text { Tilts switch slightly in his } \\
\text { direction }\end{array}$} & \multirow{2}{*}{$\begin{array}{l}\text { Speaks JM's } \\
\text { name. }\end{array}$} & \\
\hline & Facial Expression & & & & & \\
\hline
\end{tabular}




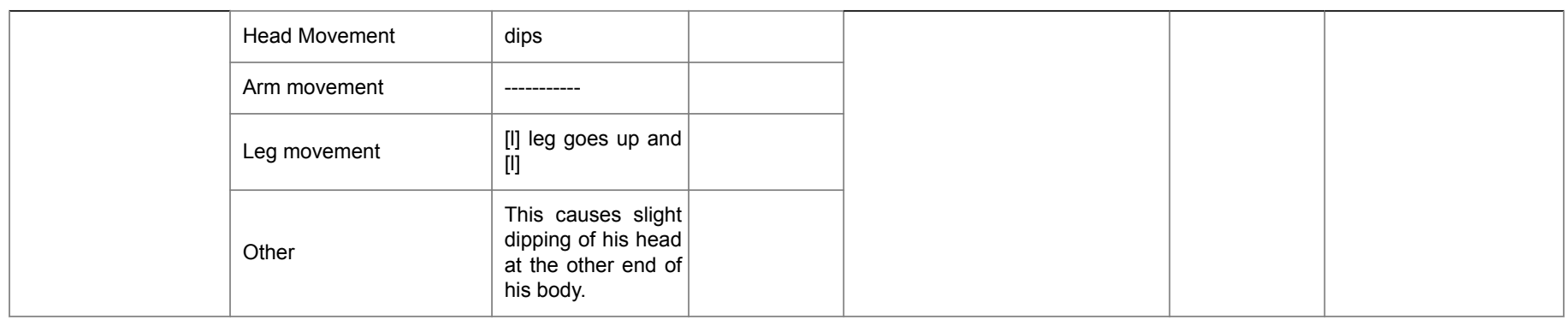

Table 1: Data transcript, Note: JM and KM are student and staff, respectively.

\section{Data analysis}

The data was analysed using a grounded theory methodology. There are several different variants of grounded theory. Strauss and Corbin's structured analytic approach is centered on the use of the conditional/ consequential matrix, which guides the research in the examination of the interplay between structure and process within the data [24]. Kathy Charmaz [25] developed a version of grounded theory that views the analytic process as being flexible. Charmaz's is a constructivist approach that acknowledges the researcher as being an interpreter of the data. In contrast this research used the analytic method of classic grounded theory [1]. Classic grounded theory suggests that analysis of the data cannot be forced and that the role of the analyst is to listen to the meanings and perspectives of the participants. [1]. Classic grounded theory analysis involves two steps that are essential components of the analytic process; these are the initial fracturing and coding of the data and the second step of memo writing, which weaves the fractured codes into a coherent theoretical framework. Eventually the core category emerges, that is the category that explains "how the participants resolve their main concern" [1].

The initial coding of the data involved examination of each incident which was described in the narrative. This meant that line by line examinations where single words, phrases and sentences and occasionally paragraphs were coded. Each line of the narrative was coded as a separate entity in itself and also as a component part of the incident. Some lines generated multiple codes. Coding consisted of writing the names of the code in the margin of the printed transcript. As the bank of codes was developed the name of each code was constantly compared with the data that had been categorized within the code, at times this resulted in the code name being changed or some of the incidents being reallocated to either a new or to other codes. This iterative process is the essence of the constant comparative process which is at the heart of grounded theory and is also a coding method that facilitates descriptive qualitative analysis. Each code was accompanied by a descriptor that named it, named the properties of the code, and detailed the incident(s) on which it was based and also where these incidents were located in the transcripts. At the end of the coding process 242 substantive codes had emerged. In most cases each code was saturated because no additional incidents emerged that added to the meaning of the codes. Subsequently the codes were grouped and sorted into categories. Again the constant comparative process was used to identify the initial names of the categories and the specific category into which each code was sorted. As with the coding process the development of the categories was a dynamic process during which the number and names of the categories changed considerably in the early stages. Eventually seven categories emerged, one of which was the core category.
By way of illustration of the coding process table 2 is an example of one of the 242 codes. Each incident is described and located in the video tape, the properties that the incidents share in common are stated and the code name that sums up the action inherent in the incidents is stated (Table 2).

\begin{tabular}{|c|c|c|c|}
\hline Code. & Properties & The incident & $\begin{array}{l}\text { Located in } \\
\text { data: Tapel } \\
\text { Recording } \\
\text { number }\end{array}$ \\
\hline \multirow[b]{2}{*}{$\begin{array}{l}\text { Providing } \\
\text { stimulus- } \\
\text { Object }\end{array}$} & Object used as stimulus. & \multirow{2}{*}{$\begin{array}{l}\text { Ball is sent by } \\
\mathrm{KM} \text { to JM } \\
\text { who is over } \\
\text { the cylinder }\end{array}$} & \multirow[b]{2}{*}{ JM 5-7.36. } \\
\hline & $\begin{array}{l}\text { Object displayed by staff in } \\
\text { near environment of } \\
\text { participant. }\end{array}$ & & \\
\hline & & $\begin{array}{lr}\text { Tigger } & \text { [toy } \\
\text { animal] } & \text { left } \\
\text { between } & \text { JM's } \\
\text { hands } & \end{array}$ & JM 6-10.32. \\
\hline \multirow{4}{*}{-} & \multirow{4}{*}{ 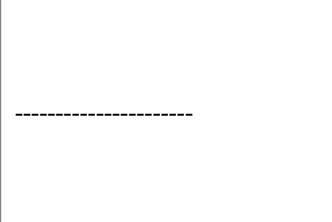 } & \multirow{4}{*}{$\begin{array}{lr}\text { Ball put } \\
\text { beside JM's } \\
\text { hand }\end{array}$} & JM 6-10.37 \\
\hline & & & JM 6-10.45 \\
\hline & & & JM 6-10.57. \\
\hline & & & JM 6-10.59 \\
\hline- & & $\begin{array}{l}\text { Switch } \\
\text { positioned } \\
\text { near JM. }\end{array}$ & $\begin{array}{l}\mathrm{JM} 16-17.27 \\
\text { and } 17.34 .\end{array}$ \\
\hline- & & $\begin{array}{l}\text { AL shows } \\
\text { book to TK, } \\
\text { book pages } \\
\text { flap open, }\end{array}$ & TK 5-38.16 \\
\hline- & & $\begin{array}{l}\text { M brings bird } \\
\text { on a track } \\
\text { across TK's } \\
\text { line of vision, } \\
\text { his follows it. }\end{array}$ & TK6-51.35 \\
\hline
\end{tabular}

Table 2: Codes, Note: Al, M and KM are staff and TK and JM are students.

The second step in the classic grounded theory analysis is the rebinding together of the fractured data. This was achieved by the writing of memos. Memos were written from the start of the coding process but initially they were comments on the codes and the incidents that were being analysed and were tentative and unclear. As the coding process continued the memos started to identify possible theoretical codes, that is, codes that identify patterns in the data and 
specify hypotheses that name those patterns [26]. In effect the memos generated theoretical codes that clarified the relationships between the seven categories and the codes that were contained in them. These codes were setting, being, stimulus, attention, engagement, action, and the core category: attuning. The whole process can be construed as taking an amorphous mass of data, breaking it down into substantive codes: the vertical columns of the theoretical framework and identifying the theoretical codes that constituted the horizontal rows of the framework. The theoretical codes effectively clarify the nature of the relationships that are inherent in the theoretical framework. The coding and memo writing process have been described in some detail with the twofold intention of explaining how the constant comparative method might be used to analyse a narrative based on observational data into a descriptive framework and also how memos might be used to develop theory from this type of data.

\section{Robustness of the data}

The validity and reliability of qualitative research is supported by the provision of evidence regarding the confirmability, dependability, transferability and credibility of the data [27]. A comprehensive diary of the complete research process was made and so an audit trail was readily available to support the confirmability and dependability of the study. As a way of assuring the trustworthiness of the data, the completed tapes of each interaction were shown to the non-disabled member of the communication dyad. Key parts of the interaction were observed and where the meaning of the interactions was not clear agreement on the resolution of the meaning of those sections was achieved. Evidence to support the transferability of the findings is obtained by the application of the findings to practice and that post hoc test has yet to be applied. By way of contrast these concepts do not directly apply in the development of theory that is grounded in the data, instead the concepts of fit, relevance, work and modifiability apply. These loosely equate to the credibility (fit), transferability (relevance), confirmability (work) and as such the same evidence applies to support these criteria.

\section{Limitations of the method}

The main limitation of the method is that the analysis of video recorded observation of behavior in such detail is time consuming. Transcription of one minute of video took approximately five and a half hours. Coding of that material was an extraordinarily lengthy process Goldman and McDermott [28] support the contention that detailed analysis takes time as does Schonfeld who videotaped a student playing a computer game and found that it took an unspecified number of researchers 18 months to analyse a 7 hour tape, he commented that in terms of thick description of an event, this description was "thicker than most" [12]. The 25 minutes of analysed video that was the primary data for this research project took many months for one researcher to transcribe, code and analyse, were such data to be coded by multiple researchers the time could be greatly reduced.

\section{Results and Discussion}

The central question that this method answers is: is it possible to use video as an observational tool to gather qualitative data that can be micro analysed and which might then provide insights into behavior that were previously not obtainable? The answer is a strong affirmative. The secondary questions are what type of insights does this method provide? What individual behaviors can be better understood? How can critical incidents be analysed? What understanding might be obtainable using this method and can it offer insight into the relationship between behaviors; that is how does one behavior act to cause impact on or have an effect on another? The answers to these questions are less easily determined.

The method offers a capacity to develop a detailed description of the micro behaviors that constitute a social interaction or an individual's behaviors in any particular setting. Video is the required hardware to achieve this; it has the capacity to reveal the forms of an interaction though the use of repeated viewings as well as slow motion and multiple perspectives [29]. Video may also reveal the "sequence structure and flow of an interaction" [30]. The method uses video to identify a comprehensive record of visible behaviors and vocalizations that occur, however there is a caveat which constitutes one of the limitations of the method, that is it requires assiduous analysis which is very time consuming. Goldman and McDermott note that "if looked at carefully enough, where carefully means an hour of transcription and analysis per second of videotape, every behavior, no matter how bizarre or seemingly nonresponsive, is part of a coherent string of behavior developed across persons and across time" [28]. This is the beauty of the method; it reveals what was previously not known. It can describe events in unprecedented detail, it reveals micro-behaviors such as slight movements of a person's head, limbs or eye gaze that are reactions to or stimuli for the actions of others in the dyad. These actions are not obvious in real time observation; however video opens them up for analysis.

\section{Application of the method}

This research study examined the behaviors and communications of a group of people who have extreme difficulty interacting meaningfully with non-disabled people, namely people with profound intellectual and multiple disability. By implication the method has potential application to reveal the behaviors and communications of people with severe, profound and complex disabilities. Other groups of people who have major communication difficulties such as people on the autistic spectrum, those with severe dementias and possibly those in persistent vegetative states might also benefit from the use of such a method. Video is already used for the analysis of specific affective traits such as social anxiety in children [31], educational processes such as the relationship of gesture to mathematical learning [32] and early childhood learning [11]. Unlocking hidden affective and communicative behaviors would seem to be the primary capability of this method; however that is perhaps simply a mechanism to the discovery of deeper and more complex levels of behavioral manifestations and interpersonal communications. In the light of such a thought the method might also be used to analyse critical incidents in health care, educational or business practice where observation, description and analysis of the detail of interactional patterns is of importance. This method, although primarily likely to be used to provide qualitative data for descriptive analysis, also offers the possibility of developing inductive explanatory theory that is grounded in the data of the substantive field of inquiry.

The relationship of micro-behaviors to macro-behaviors reveals another potential of the method that is the possibility of revealing new insights into how macro systems work. There is a general assumption that with regard to human behavior that macro patterns are the emergent product of micro-behaviors [33,34]. Micro-behaviors are regarded as constituting the subparts of the macro system [34]; they therefore are the determinants of how macro systems work. It seems 
reasonable to hypothesize that if it is possible to identify the relationships between the micro-behaviors that comprise a macro system the operation of the system might then become evident, this interaction between the micro and the macro level of analysis allows for an indentation of the different levels of data and the consequent emergence of theoretical frameworks that encompass both [29]. Because this method has the capability primarily to identify human micro-behaviors it would seem to be fair to assume that it is in the area of the operation of teams, groups and human systems that this method has most to offer. Some have hypothesized that the interpersonal (macro) experience of individuals within a team is a determinant of the performance of that team [35], whereas others [36] consider that the perception of micro communications (micro) is fundamental in the process of the perception of nursing care by patients. In considering both of these analytic possibilities this qualitative methodology offers the possibility to identify both micro and macro-behaviors in interpersonal processes and it seems reasonable to conclude that it has the potential to reveal new understandings of the behaviors of what individuals do, how they behave in groups and then by implication how systems operate.

\section{Conclusion}

The explication of the intricacies of the micro-behaviors of individuals is as yet a field of the behavioral sciences that is only opening up. Equally the development of a method that identifies micro-behaviors and offers the potential to classify them and to develop theoretical explanations for the relationships between them is a new development in the field of qualitative inquiry, this article has explored the roots of such a method. Furthermore this article has described in detail how the method operates, its limitations and some of the applications that it might have. It has also attempted to illuminate the point that was made at the start namely that here is a qualitative methodology that can describe and process precise, micro analytic observational data. In conclusion to paraphrase Schumacher [37] 'small is not only beautiful, it is insightful'.

\section{References}

1. Glaser B (1998) Doing Grounded Theory. Mill Valley. Sociology Press.

2. Morse JM (2003) Perspectives of the observer and the observed. Qual Health Res 13: 155-157.

3. UNECE (2000) Economic Commission for Europe of the United Nations "Terminology on Statistical Metadata", Conference of European Statisticians Statistical Standards and Studies, No. 53, Geneva.

4. United States Bureau of the Census (1998) Survey Design and Statistical Methodology Metadata, Software and Standards Management Branch, Systems Support Division, Washington D.C.

5. Cartwright-Hatton S, Hodges L, Porter J (2003) Social anxiety in childhood: the relationship with self and observer rated social skills. J Child Psychol Psychiatry 44: 737-742.

6. Shimmerlik S (2008) The implicit domain in couples and couples therapy. Psychoanalytic dialogues. 18: 371-389.

7. Perrin T (1997) Occupational need in severe dementia: A descriptive study. J Adv Nurs 25: 934-941.

8. Finlay WML, Anataki C, Walton C (2008) A manifesto for the use of video in service improvement and staff development in residential services for people with learning disabilities. British Journal of Learning Disabilities. 36: 227-231.

9. Pally R (2005) A neuroscience perspective on forma of intersubjectivity in infant research and adult treatment. In B Beebe, S Knoblach, J Rustin and D Sorter (Eds). Forms of intersubjectivity in infant research and adult treatment, Other Press, New York.
10. Paschler H (1998). Attention, Psychology Press, Hove.

11. Flewitt $\mathrm{R}$ (2006) Using video to investigate preschool classroom interaction: Education research assumptions and methodological practices. Visual Communication 5: 25-50.

12. Schonfeld AH (1992). On paradigms and methods: what do you do when the ones you know don't do what you want them to? Issues in the analysis of data in the form of videotapes. The Journal of Learning Sciences. 2: 179-214.

13. Roberts JE, Symons FJ, Johnson AM, Hatton DD, Boccia ML (2005) Blink rate in boys with fragile $\mathrm{X}$ syndrome: preliminary evidence for altered dopamine function. J Intellect Disabil Res 49: 647-656.

14. Lindsay WR, Pithcaithly D, Geelen N, Buntin L, Broxhole S, et al. (1997). A comparison of the effects of four therapy procedures on concentration and responsiveness in people with profound learning difficulties. Journal of Intellectual Disability Research. 41: 201-207.

15. Heacock P, Souder E, Chastain J (1996) Subjects, data, and videotapes. Nurs Res 45: 336-338.

16. Nakken H, Vlaskamp C (2007) A need for a taxonomy for profound intellectual and multiple disabilities. Journal of Policy and Practice in Intellectual Disabilities 4: 83-87.

17. Lomax H, Casey N (1998) Recording social life: reflexivity and video methodology. Sociological Research Online.

18. Grove N, Bunning K, Porter J, OlssonC (1999) See what I mean: interpreting the meaning of communications by people with severe and profound intellectual disabilities. Journal of the Applied Research in Intellectual Disabilities 12: 190-203.

19. Wilder J, Granlund M (2003) Behaviour style and interaction between seven children with multiple disabilities and their caregivers. Child Care Health Dev 29: 559-567.

20. Geertz C (1973) Thick description: Towards an interpretive theory of culture. In Geertz C, (ed). The Interpretations of Cultures: selected essays, Basic Books, New York.

21. Ryle G (1971). Collected Papers, Hutchinson. London.

22. West C (1996). Ethnography and orthography: a modest methodological proposal. Journal of Contemporary Ethnography. 25: 327-352.

23. Jefferson G (1971) A report on some difficulties encountered when using pseudonyms in research generative transcripts. Irvine, California, Department of Sociology. University of California.

24. Strauss A, Corbin J (1990). Basics of Qualitative Research: Techniques and procedures for developing grounded theory, Sage, London.

25. Brossoie N, Roberto KA, Barrow KM (2012) Making sense of intimate partner violence in late life: comments from online news readers. Gerontologist 52: 792-801.

26. Glaser B (2005) The Grounded Theory Perspective 3: Theoretical coding, Sociology Press, Mill Valley.

27. Holloway I, Wheeler S (2002) Qualitative Research in Nursing, Blackwell Science, Oxford.

28. Goldman S, McDermott R (2007). Staying the course with video analysis. In Goldman R, Pea R, Barron B and Derry S, (eds). Video Research in the Learning Sciences. Mahwah NJ, Lawrence Erlbaum Associates.

29. Haw K, Hadfield M (2011). Video in Social Science Research, Routledge, London.

30. Cibulka P (2015) When the hands do not go home: A micro-study of the role of gesture phases in sequence suspension and closure. Discourse Studies 17: 3-24.

31. Cartwright-Hatton S, Tschernitz N, Gomersall H (2005) Social anxiety in children: social skills deficit, or cognitive distortion? Behav Res Ther 43: 131-141.

32. Francaviglia M, Servidio R (2011) Gesture as a cognitive support to solve mathematical problems. Psychology. 2: 91-97.

33. Foxon TJ (2011) Complex systems methods for informing energy decision-making in cities. Paper presented at seminar of PANDA (Patterns, Nonlinear, Dynamics and Applications). Surrey. 
Citation: Griffiths CR (2015) Small is Insightful: A Method for the Microanalysis of Behaviour and Communication. J Nurs Care 4: 303 . doi: 10.4172/2167-1168.1000303

Page 7 of 7

34. Mella P (1998) Observing collectivities: The combinatory systems approach in social sciences. International Journal of Interdisciplinary Social Sciences 3: 213-224

35. Luoma J, Hamalainen RP, Saarinien E (2008) Perspectives on team dynamics: meta learning and systems intelligence. Systems Research and Behavioral Science 25: 757-767.
36. Brechin A (1998) What makes for good care? In A. Brechin, J Walmsley, J. Katz, and Peace S eds). Care Matters, Sage, London.

37. Scumacher EF (1973). Small is Beautiful, Blond and Briggs, London. 